\title{
Evaluation of Marginal Alveolar Bone Height for Early Detection of Periodontal Disease in Pediatric Population: Clinical and Radiographic Study
}

\author{
${ }^{1}$ Varun Sardana, ${ }^{2}$ Aswini Y Balappanavar, ${ }^{3}$ Shobha Deshpande, ${ }^{4}$ Anand Shigli, ${ }^{5} \mathrm{KR}$ Indushekar, ${ }^{6}$ Guneet Gogia
}

\begin{abstract}
Objectives: To establish a normal range for the radiographic distance between cementoenamel junction and alveolar bone crest and the factors affecting distances for the early assessment of periodontal disease in Dravidian pediatric population.

Methods: Fifty children aged 6 to 8 years were selected based on inclusion and exclusion criteria. Clinical and radiographic examination was performed. All the surfaces were examined starting from the distal surface of primary canine to the mesial surface of first permanent molar. The various risk factors like plaque, calculus, proximal caries, restoration and bleeding on probing were recorded. A pair of bitewing radiographs was taken for each child. Bitewing radiographs were traced and analyzed.

Results: It showed that CEJ-ABC distance in primary teeth is about $1 \pm 0.5 \mathrm{~mm}$. In the permanent teeth, it was found to be $0.6 \pm 0.5 \mathrm{~mm}$ in 6 to 8 years age group. CEJ-ABC distance was also affected by different variables like physiologic (eruption and exfoliation) and pathologic factors (plaque, calculus, dental caries, restorations, stainless steel crowns, bleeding on probing and probing depth).
\end{abstract}

Conclusion: CEJ-ABC distances greater than $2.5 \mathrm{~mm}$ should be considered under recall and follow-up. Children and adolescents susceptible to periodontal disease should be identified by radiographic means as early as possible in order to prevent the advance of an otherwise possibly destructive disease. The

${ }^{1}$ Associate Professor, ${ }^{2}$ Assistant Professor, ${ }^{3-5}$ Professor and Head, ${ }^{6}$ Reader

${ }^{1}$ Department of Pedodontics and Preventive Dentistry, ITS Institute of Dental Sciences, Muradnagar, Ghaziabad, Uttar Pradesh, India

${ }^{2}$ Department of Public Health Dentistry, Maulana Azad Institute of Dental Sciences, New Delhi, India

${ }^{3}$ Department of Pedodontics and Preventive Dentistry, Yerala Dental College, Mumbai, Maharashtra, India

${ }^{4}$ Department of Pedodontics and Preventive Dentistry, Bharti Vidyapeeth Institute of Dental Sciences, Sangli, Maharashtra India

${ }^{5}$ Department of Pedodontics and Preventive Dentistry, Sudha Rustagi Dental College, Faridabad, Haryana, India

${ }^{6}$ Department of Periodontics, Rama Institute of Dental Sciences Kanpur, Uttar Pradesh, India

Corresponding Author: Varun Sardana, Associate Professor Department of Pedodontics and Preventive Dentistry, ITS Institute of Dental Sciences, Muradnagar, Ghaziabad, Uttar Pradesh, India, e-mail: drvarunsardana1978@gmail.com concept of oral health examination and treatment must include examination of the periodontal status of the patient.

Keywords: CEJ-ABC distance, Primary dentition, Radiographic examination, Gingivitis, Periodontitis, Alveolar bone.

How to cite this article: Sardana $V$, Balappanavar $A Y$, Deshpande S, Shigli A, Indushekar KR, Gogia G. Evaluation of Marginal Alveolar Bone Height for Early Detection of Periodontal Disease in Pediatric Population: Clinical and Radiographic Study. J Contemp Dent Pract 2014;15(1):37-45.

Source of support: Nil

Conflict of interest: None

\section{INTRODUCTION}

Dental disease continues to be a common health problem among children, referred to as 'the silent epidemic'. ${ }^{1}$ The periodontal diseases can be present in children and adolescents, ranging from reversible conditions, limited to the gingival tissues to those characterized by destruction of the periodontal tissue and alveolar bone which may jeopardize the longevity of the deciduous or permanent dentition. ${ }^{1-3}$ However, little attention has been paid to the periodontitis in children due to the shorter life time of primary dentition and slower rate of progression of periodontal diseases in children. $^{4}$

In the primary dentition periodontitis is rare, if present, results in severe periodontal destruction and is associated with systemic diseases, ${ }^{5}$ local trauma caused by habits or inadequate restorations; and in cases with juvenile periodontitis and/or prepubertal periodontitis. ${ }^{6}$ A small attachment loss, or apical migration of the junctional epithelium in the human primary teeth has no clinical significance and does not necessarily denotes the presence of periodontitis as it may be physiological. ${ }^{4}$

Extensive proximal caries and presence of stainless steel crown resulting in food impaction and plaque retention interdentally has shown to be one of the factors for alveolar bone loss. ${ }^{4}$ Previous studies have shown that children who develop alveolar bone loss in the primary dentition may have an increased likely hood to develop the same at older ages and may facilitate the establishment of periodontal disease in the adjacent permanent teeth; hence, the need for the early diagnosis of marginal alveolar bone loss in the primary 
dentition is necessary to judge individuals susceptible to periodontal breakdown. ${ }^{7,8}$

There are various methods which have been used for the diagnosis of alveolar bone loss. Radiographic methods have frequently been used in epidemiologic studies on periodontitis. Measurement of CEJ-ABC distance above threshold values may indicate an early stage of periodontal disease in primary teeth and/or a tendency of patient to develop periodontal disease. ${ }^{3}$

There are very few studies which tried to explore the normal distance between cementoenamel junction and alveolar bone crest, still there is an immense need to find out the normal range in Indian children due to lack of studies in India. Hence, this study was conducted with the aim to determine the normal range of the distance between cementoenamel junction (CEJ) and alveolar bone crest (ABC) in posterior areas of dentition. The objectives were to evaluate any abnormal bone resorption of alveolar bone crest with respect to predisposing factors (proximal caries, proximal restoration, plaque and calculus) for the early assessment of periodontal disease.

\section{METHODS}

The present cross-sectional, single blind study was conducted among children aged 6 to 8 years attending the OPD of Department of Pediatric Dentistry. KLEs' Institute of Dental Sciences, Belgaum. Ethical approval for study was obtained from institution's ethical committee and informed consent was obtained from the parents of children.

Based on the OPD per day in the department and secondary literature, the sample size of 50 was found to be appropriate. Subjects aged 6 to 8 years with no systemic disease, ${ }^{9}$ with primary molars, primary canine and first permanent molars fully erupted and in occlusion and CEJ clearly visible if stainless steel crowns are placed were included in the study. The subjects excluded were subjects undergoing any orthodontic treatment, ${ }^{8}$ drugs or antibiotic therapy since last 3 months, technical quality of the radiographs is poor or less than $60 \%$ of available surfaces are readable, teeth with pulpal or furcal involvement with periapical radiolucency ${ }^{6}$ and if the adjacent proximal surfaces overlapped to the extent that less than half of outer enamel curvature between CEJ and the contact point was discernible.

A special format designed to record general information and other pertinent variables was developed.

\section{Clinical Examination}

Measurements were made at four sites in all primary molars (mesiobuccal, distobuccal, mesiolingual, distolingual), two sites in all primary canines (distobuccal, distolingual), two sites in all first permanent molars (mesiobuccal, mesiolingual). The highest score recorded for each proximal surface was used for the evaluation. ${ }^{3}$ The clinical examination was carried through out by the investigator himself and was assisted by recording clerk for recording of the findings. The various risk factors like plaque (Silness and Loe plaque index,1964), calculus, proximal caries, restoration and bleeding on probing were recorded. Calculus was checked for the presence and absence using plane mouth mirror and sickle explorer. Proximal caries was checked with a plane mouth mirror and explorer. Probing depth of sulcus was checked using William's periodontal probe and plane mirror and the score of less than $4 \mathrm{~mm}$ was assigned ' 0 ' and more than $4 \mathrm{~mm}$ of pocket was assigned ' 1 '.

\section{Procedure for Radiography}

A pair of bitewing radiographs (Kodak Ectaspeed) was taken for each child. The central beam of X-ray machine collimator (Satelec image $\mathrm{X}, 70^{\circ} \mathrm{Kvp}, 8 \mathrm{~mA}, 0.415^{\circ} \mathrm{KVA}$, total filtration $-2.5 \mathrm{~mm} \mathrm{A1}$.) was directed at $+10^{\circ}$ vertical angulation and also central beam was directed through the contact areas between the teeth with the help of Rinn bitewing positioning device. ${ }^{10,11}$ All radiographs were taken by one operator, i.e. investigator himself. Prior to the radiographic procedure instructions were given to the subjects. Patient's head was positioned such that the upper arch is parallel to the floor and the midsagittal plane is perpendicular to floor. Lead apron and thyroid collar were secured on the patient and all objects were removed from mouth viz removable appliances chewing gum, toffee that may interfere with film placement and exposure as well as spectacles.

All bitewing radiographs were viewed in high intensity illuminator. The bite wing radiographs were traced on tracing paper with fine pencil and scale (Fig. 1). The bite wing radiographs were kept above the illuminator and above this tracing paper was placed and teeth were traced along with CEJ-ABC distance on that tracing paper. Parallel lines touching the highest point on cusp on each tooth and subsequent parallel lines drawn from CEJ and highest point of alveolar crest of alveolar bone was drawn as reference line (Fig. 2). A perpendicular line was dropped from occlusal reference line touching the cementoenamel junction and alveolar bone crest parallel lines. ${ }^{9}$ For the accuracy the distance from CEJ to alveolar crest which is perpendicular to occlusal surface of the distal aspect of maxillary/mandibular primary canine, mesial and distal aspect of first and second primary molar and mesial aspect of first permanent molar were measured by Digimatic Caliper (No-99 MAD005W, Serial No. 500 Mitutoyo measuring instrument (Suzhou) Co. Ltd.) $)^{9}$ (Fig. 3). 


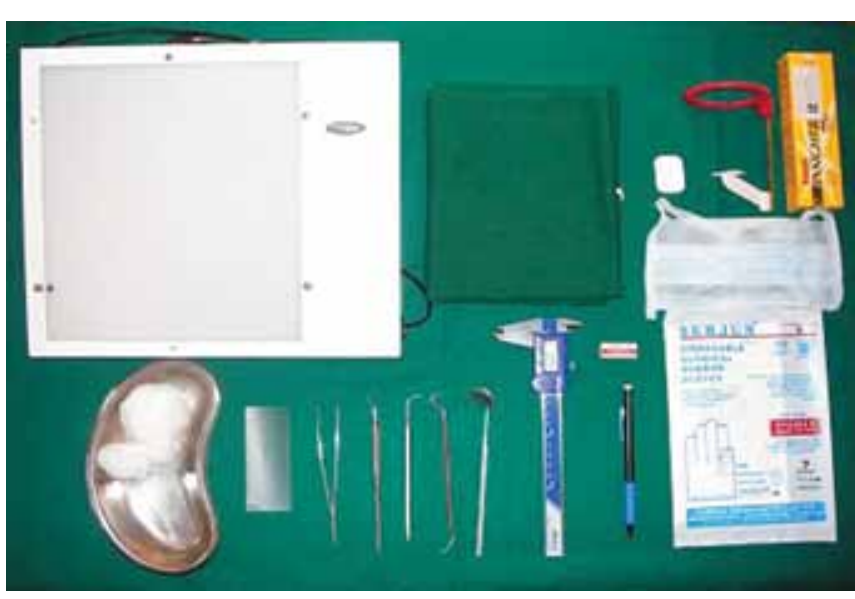

Fig. 1: Armamentarium used in the study

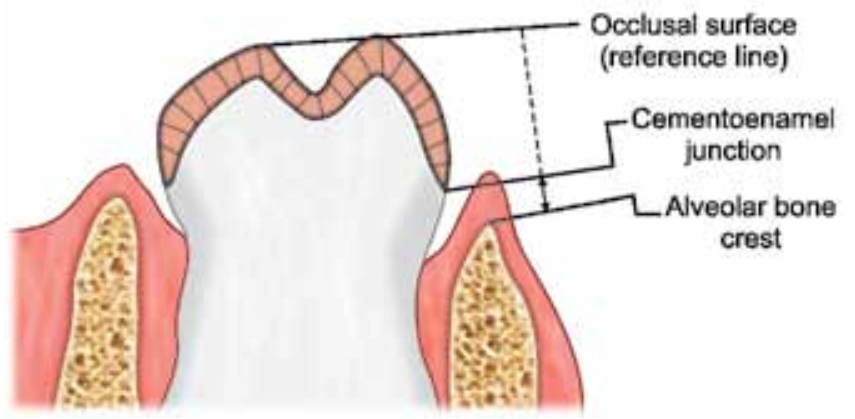

Fig. 2: Line diagram depicting procedure for tracing and analyzing radiograph

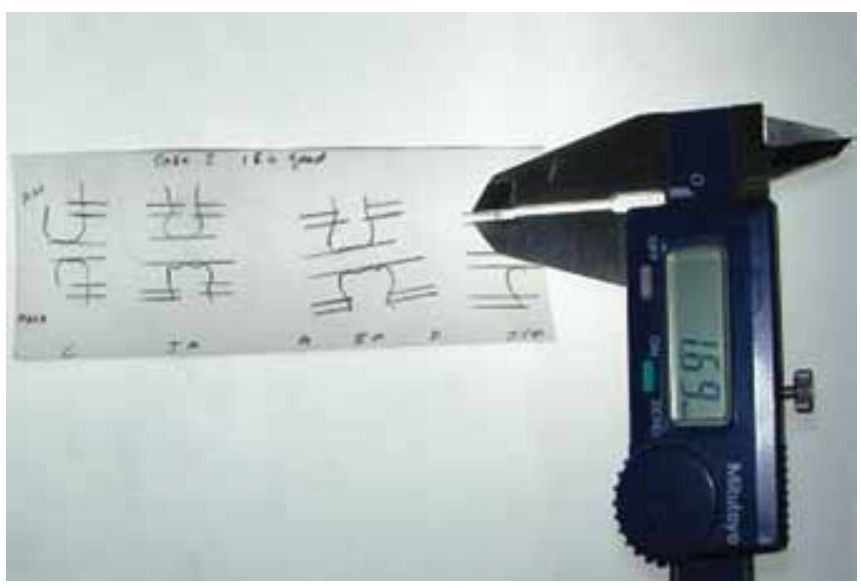

Fig. 3: Measurement with Digimatic Caliper

For intraexaminer variability, every alternate subject's bite wing radiographs were taken and retraced after 4 weeks. The bitewing X-rays were analyzed according to criteria., $3,4,12,13$

Group I (negative) - CEJ-ABC distance $<2 \mathrm{~mm}$. Group II (questionable) - CEJ-ABC distance between 2 and $3 \mathrm{~mm}$. Group III (definite) - CEJ-ABC distance $>3 \mathrm{~mm}$.

\section{RESULTS}

The data collected was compiled and tabulated in Microsoft excel and analysis was done using SPSS software (version 13). For all the tests, a p-value of 0.05 or less was considered as statistically significant at confidence interval of $95 \%$. chi-square test, Z-test and paired t-test were used for analysis.

The observations of the radiographs were put under three groups. These groups were further divided into different levels, i.e. $0,0.51$ to $1.0,1.01$ to $1.50,1.51$ to $2.0,2.01$ to $2.50,2.51$ to 3.0 and 3.01 to $4.0 \mathrm{~mm}$, to make interpretations easier. Fifty subjects of age group 6 to 8 years completed the study among which 15 subjects were of 6 years age group, 18 belonged to 7 years and 17 belonged to 8 years. The total no. of sites examined was 914 .

Among the Dravidian children of 6 to 8 years age groups, the CEJ-ABC distances in normal healthy children in the present study ranged between 0 and $1.60 \mathrm{~mm}$ (Table 1). In deciduous dentition, the least $\mathrm{CEJ}-\mathrm{ABC}$ distance was observed in mandibular first primary molar mesial aspect $(0.79 \pm 0.6 \mathrm{~mm})$ whiles the maximum with maxillary deciduous canine distal aspect $(1.49 \pm 0.4 \mathrm{~mm})$. In permanent dentition, the least distance was seen with maxillary first permanent molar mesial aspect $(0.59 \pm 0.5 \mathrm{~mm})$, this was the least score observed in the study. The distance was found to be less in maxillary first permanent molar when compared to mandibular counterpart.

As the age increased the mean CEJ-ABC distance also increased which was found to be statistically nonsignificant $\left(\chi^{2}=14.3, p=0.28\right.$, nonsignificant $)$. The total no. of sites examined in the age group of 6 years is 236 , for 7 years are 342 and 336 sites in 8 years (Table 2). Total 26 males were examined with 476 sites, among which maximum sites (202) where having level of 1.01 to $1.50 \mathrm{~mm}$ (mean $\pm \mathrm{SD}=1.25$ $\pm 0.5 \mathrm{~mm}$ ). Twenty females were examined with 438 sites that showed maximum sites (199) in a CEJ-ABC distance level of 1.01 to $1.50 \mathrm{~mm}$ (mean $\pm \mathrm{SD}, 1.14 \pm 0.47 \mathrm{~mm}$ ). Comparison revealed a significant difference between male and female CEJ-ABC distances $\left(\chi^{2}=22.0, p=0.001\right)$ as depicted in Table 3.

\section{Distribution on Different Teeth and Sites}

A total of 100 sites were examined in fifty subjects on mesial aspect maxillary primary second molars with mean \pm $\mathrm{SD}, 1.15 \pm 0.4 \mathrm{~mm}$ ranging between 0 and $2.11 \mathrm{~mm}$ with maximum sites (48) having CEJ-ABC distance in a level of 1.01 to $1.50 \mathrm{~mm}$ and the least sites (0) were in 2.51 to $3.0 \mathrm{~mm}$ level. Ninety-eight sites belonged to groups I and II sites to group II. Among 50 children, 71 sites were evaluated on distal aspect of maxillary primary second molars with mean $\pm \mathrm{SD}$ distance of $1.10 \pm 0.4 \mathrm{~mm}(0-1.89 \mathrm{~mm})$. The maximum sites were lying in the level of 1.01 to $1.50 \mathrm{~mm}$ and minimum of zero in level of 2.01 to $2.50 \mathrm{~mm}$ and above. All the sites were in group I (71). Total of 100 sites were examined on mesial aspect of maxillary primary first molars having 
Table 1: Distribution of mean CEJ-ABC distances according to the different age groups and the number of sites examined

\begin{tabular}{|c|c|c|c|c|c|c|c|}
\hline \multirow[t]{3}{*}{ Tooth } & \multicolumn{6}{|c|}{ Age (males and females) } & \multirow{3}{*}{$\begin{array}{l}\text { Mean } \pm S D \\
\text { CEJ-ABC } \\
\text { distance } \\
(\mathrm{mm})\end{array}$} \\
\hline & \multicolumn{2}{|c|}{6 years } & \multicolumn{2}{|c|}{7 years } & \multicolumn{2}{|c|}{8 years } & \\
\hline & $\begin{array}{l}\text { Mean CEJ- } \\
\text { ABC distance } \\
(\mathrm{mm})\end{array}$ & No. of sites & $\begin{array}{l}\text { Mean CEJ- } \\
\text { ABC distance } \\
(\mathrm{mm})\end{array}$ & No. of sites & $\begin{array}{l}\text { Mean CEJ- } \\
\text { ABC distance } \\
(\mathrm{mm})\end{array}$ & No. of sites & \\
\hline $16+26(M)$ & $0.48 \pm 0.3$ & 6 & $0.53 \pm 0.4$ & 27 & $0.65 \pm 0.5$ & 32 & $0.59 \pm 0.5$ \\
\hline $55+65(M)$ & $1.12 \pm 0.5$ & 30 & $1.17 \pm 0.4$ & 36 & $1.17 \pm 0.4$ & 34 & $1.15 \pm 0.4$ \\
\hline $55+65(D)$ & $1.13 \pm 0.3$ & 9 & $1.05 \pm 0.4$ & 29 & $1.13 \pm 0.4$ & 33 & $1.15 \pm 0.4$ \\
\hline $54+64(M)$ & $1.0 \pm 0.4$ & 30 & $1.10 \pm 0.6$ & 36 & $1.21 \pm 0.5$ & 34 & $1.11 \pm 0.5$ \\
\hline $54+64(D)$ & $1.24 \pm 0.3$ & 30 & $1.16 \pm 0.4$ & 36 & $1.39 \pm 0.5$ & 34 & $1.26 \pm 0.4$ \\
\hline $53+63(D)$ & $1.39 \pm 0.3$ & 30 & $1.45 \pm 0.5$ & 35 & $1.60 \pm 0.4$ & 34 & $1.49 \pm 0.4$ \\
\hline $36+46(\mathrm{M})$ & $0.48 \pm 0.4$ & 7 & $0.76 \pm 0.5$ & 30 & $0.89 \pm 0.5$ & 33 & $0.79 \pm 0.5$ \\
\hline $75+85(M)$ & $1.24 \pm 0.3$ & 30 & $1.30 \pm 0.5$ & 36 & $1.15 \pm 0.4$ & 34 & $1.23 \pm 0.4$ \\
\hline $75+85(D)$ & $0.93 \pm 0.2$ & 10 & $1.24 \pm 0.5$ & 34 & $1.11 \pm 0.4$ & 33 & $1.14 \pm 0.4$ \\
\hline $74+84(\mathrm{M})$ & $0.63 \pm 0.5$ & 30 & $0.88 \pm 0.6$ & 35 & $0.85 \pm 0.5$ & 33 & $0.79 \pm 0.6$ \\
\hline $74+84(D)$ & $1.38 \pm 0.4$ & 30 & $1.37 \pm 0.4$ & 36 & $1.41 \pm 0.4$ & 34 & $1.39 \pm 0.4$ \\
\hline $73+83(D)$ & $1.39 \pm 0.4$ & 30 & $1.45 \pm 0.4$ & 34 & $1.52 \pm 0.5$ & 33 & $1.44 \pm 0.5$ \\
\hline
\end{tabular}

Table 2: Distribution and comparison of mean CEJ-ABC distance with age

\begin{tabular}{|c|c|c|c|c|c|c|c|c|c|c|}
\hline \multirow{2}{*}{$\begin{array}{l}\text { Age } \\
\text { (yrs) }\end{array}$} & \multirow{2}{*}{$\begin{array}{l}\text { No. of } \\
\text { children }\end{array}$} & \multirow{2}{*}{$\begin{array}{l}\text { No. of } \\
\text { sites }\end{array}$} & \multicolumn{5}{|c|}{ Group I } & \multicolumn{2}{|c|}{ Group II } & \multirow[t]{2}{*}{ Mean $\pm S D$} \\
\hline & & & 0 & $0.1-0.5$ & $0.51-1.0$ & $1.01-1.5$ & $1.51-2.0$ & $2.01-2.50$ & $2.51-3.0$ & \\
\hline 6 & 15 & 236 & $10 \pm 4.2$ & $9 \pm 3.8$ & $57 \pm 24.2$ & $118 \pm 50$ & $37 \pm 15.7$ & $3 \pm 1.3$ & $2 \pm 0.8$ & $1.16 \pm 0.46$ \\
\hline 7 & 18 & 342 & $11 \pm 3.2$ & $17 \pm 5.0$ & $95 \pm 27.8$ & $143 \pm 41.8$ & $57 \pm 16.7$ & $17 \pm 5.0$ & $2 \pm 0.6$ & $1.19 \pm 0.51$ \\
\hline 8 & 17 & 336 & $11 \pm 3.3$ & $16 \pm 4.8$ & $81 \pm 24.1$ & $140 \pm 41.7$ & $72 \pm 21.4$ & $15 \pm 4.5$ & $1 \pm 0.3$ & $1.22 \pm 0.49$ \\
\hline Total & 50 & 914 & $32 \pm 3.5$ & $42 \pm 4.6$ & $233 \pm 25.5$ & $401 \pm 43.9$ & $166 \pm 18.2$ & $35 \pm 3.8$ & $5 \pm 0.5$ & $1.20 \pm 0.49$ \\
\hline \multicolumn{3}{|c|}{ Age vs bone height } & \multicolumn{5}{|c|}{$\chi^{2}=14.3, \mathrm{df}=12, p=0.28, \mathrm{NS}$} & & & $p>0.05, N S$ \\
\hline
\end{tabular}

HS: Not significant

Table 3: Comparison of CEJ-ABC distance between male and female children

\begin{tabular}{|c|c|c|c|c|c|c|c|c|c|c|}
\hline \multirow[t]{2}{*}{ Gender } & \multirow{2}{*}{$\begin{array}{l}\text { No. of } \\
\text { children }\end{array}$} & \multirow{2}{*}{$\begin{array}{l}\text { No. of } \\
\text { sites }\end{array}$} & \multicolumn{5}{|c|}{ Group I } & \multicolumn{2}{|c|}{ Group II } & \multirow{2}{*}{$\frac{\text { Mesial + Distal }}{\text { Mean } \pm S D}$} \\
\hline & & & 0 & $0.1-0.5$ & $0.51-1.0$ & $1.01-1.5$ & $1.51-2.0$ & $2.01-2.50$ & $2.51-3.0$ & \\
\hline Male & 26 & 476 & $13 \pm 2.7$ & $26 \pm 5.5$ & $103 \pm 21.6$ & $202 \pm 42.4$ & $105 \pm 22.1$ & $23 \pm 4.8$ & $4 \pm 0.8$ & $1.25 \pm 0.51$ \\
\hline Female & 24 & 438 & $19 \pm 4.3$ & $16 \pm 3.7$ & $130 \pm 29.7$ & $199 \pm 45.5$ & $61 \pm 13.9$ & $12 \pm 2.7$ & $1 \pm 0.2$ & $1.14 \pm 0.47$ \\
\hline Total & 50 & 914 & $32 \pm 3.5$ & $42 \pm 4.6$ & $233 \pm 25.5$ & $401 \pm 43.5$ & $166 \pm 18.2$ & $35 \pm 3.8$ & $5 \pm 0.3$ & $1.20 \pm 0.49$ \\
\hline \multicolumn{3}{|c|}{ Male vs female } & \multicolumn{5}{|c|}{$\chi^{2}=22.0, \mathrm{df}=6, p=0.001, \mathrm{HS}$} & & & $\begin{array}{l}Z=3.41 \\
p=0.001, H S\end{array}$ \\
\hline
\end{tabular}

HS: Highly significantly

mean $\pm \mathrm{SD}, 1.11 \pm 0.5 \mathrm{~mm}(0-2.93 \mathrm{~mm})$. Observations showed maximum number of sites at 1.01 to $1.50 \mathrm{~mm}$ and minimum at 2.51 to $3.0 \mathrm{~mm}$. The 95 sites were less than $2 \mathrm{~mm}$ and 5 sites in 2 to $3 \mathrm{~mm}$. Total of 100 sites were examined on distal aspect of maxillary primary first molars having mean $\pm \mathrm{SD}, 1.26 \pm$ $0.4 \mathrm{~mm}(0.44-2.31 \mathrm{~mm})$. Maximum subjects (41) were found in a CEJ-ABC distance level of 1.01 to $1.50 \mathrm{~mm}$ (group I) (Graph 1).

One hundred sites were observed on mesial aspect of mandibular second deciduous molar with mean $\pm \mathrm{SD}, 1.23$ $\pm 0.4 \mathrm{~mm}(0-2.48 \mathrm{~mm})$ and maximum sites (47) present in distance level of 1.01 to $1.50 \mathrm{~mm}$. More sites were present in group I (96) and minimum in group II (4). Total of 77 sites on distal aspect of mandibular second deciduous molar were examined having mean $\pm \mathrm{SD}, 1.14 \pm 0.4 \mathrm{~mm}(0-3.73 \mathrm{~mm})$. Maximum sites (44) were found in group I. Only one site showed to have distance of $3.73 \mathrm{~mm}$ (group III). Ninety-eight sites were evaluated on mesial aspect of mandibular first deciduous molar and mean, $0.79 \pm 0.6 \mathrm{~mm}$ in a range of 0 to $2.44 \mathrm{~mm}$, with maximum (34) sites in a CEJ-ABC distance level of 0.51 to $1.0 \mathrm{~mm}$ and minimum of two sites in a level of 2.01 to $2.50 \mathrm{~mm}$. Ninety-six sites belonged to groups I and II sites in group II. In total, 100 sites were examined in distal aspect of mandibular first deciduous molar with mean 
$\pm \mathrm{SD}, 1.39 \pm 0.4 \mathrm{~mm}(0.50-3 \mathrm{~mm})$. Maximum CEJ-ABC distance was found in a level of 1.01 to $1.50 \mathrm{~mm}$ with 57 sites. Total number of sites in group I was 96 and, in group II, there were for sites only (Graph 2).

Aggregate of 99 sites were evaluated on distal aspect of maxillary primary canines with mean $\pm \mathrm{SD}$, of $1.49 \pm 0.4 \mathrm{~mm}$ (0.30-2.42 mm). Sites in CEJ-ABC were more in group I (89) followed by group II (10) sites and group III (0). On distal aspect of mandibular primary canines, the number of sites examined was 97 with mean $\pm \mathrm{SD}, 1.44 \pm 0.5 \mathrm{~mm}$ $(0-2.60 \mathrm{~mm})$. Forty-three sites were having distance of 1.01 to $1.50 \mathrm{~mm} .84,12$ and 0 sites were lying in groups I, II and III respectively. A total of 65 sites were examined on mesial aspect of maxillary permanent first molars with mean $\pm \mathrm{SD}, 0.59 \pm 0.5 \mathrm{~mm}(0-2.0 .3 \mathrm{~mm})$. Maximum sites (30) were present in 0.51 to $1.0 \mathrm{~mm}$ and no sites were found greater than $2.50 \mathrm{~mm}$. Sixty-four, 1 and 0 sites, were belonging to groups I, II and III respectively. Seventy sites on mesial aspect mandibular permanent first molars in total from fifty subjects were evaluated and mean $\pm \mathrm{SD}, 0.79 \pm$ $0.5 \mathrm{~mm}$ among which maximum sites (31) were present in CEJ-ABC distance level of 0.51 to $1.0 \mathrm{~mm}$ and a minimum of one site in level of 2.01 to $2.50 \mathrm{~mm}$. Group I shows 69 sites and only one site in group II (Graph 3).
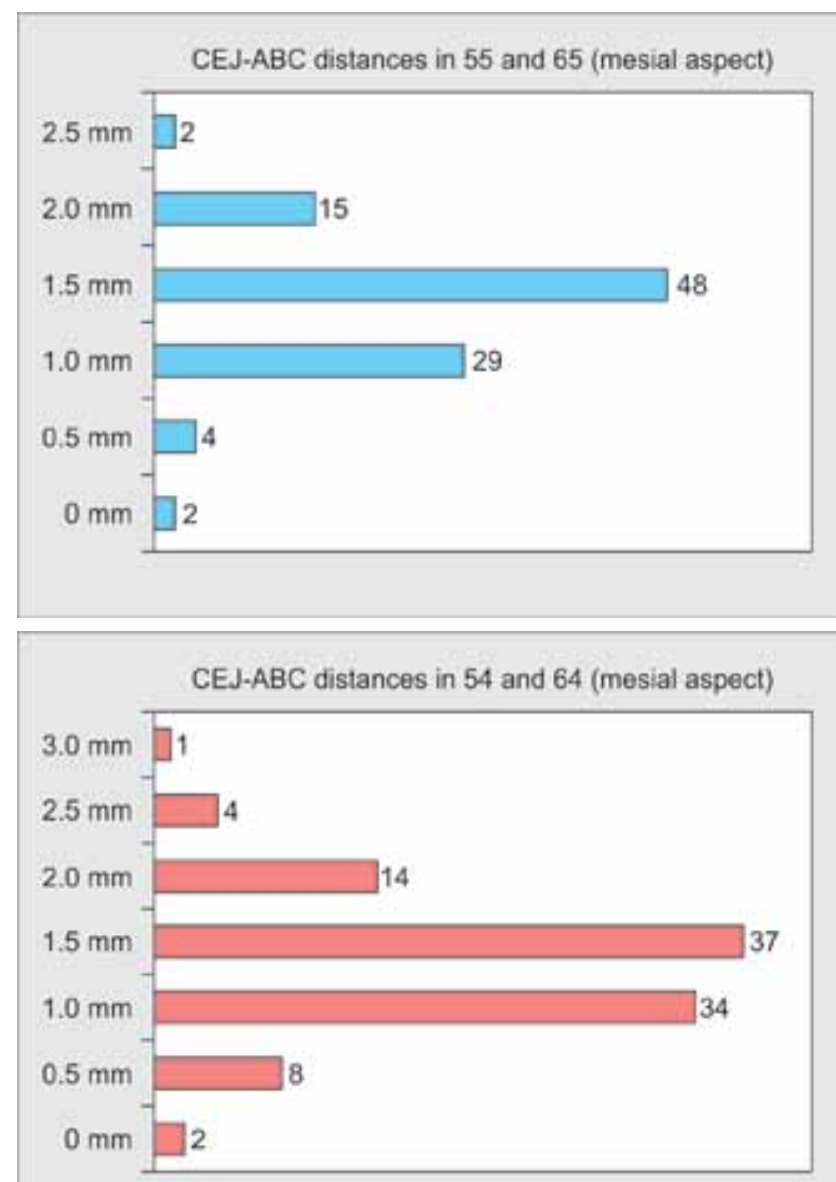

\section{Variables and CEJ-ABC Distance}

A total of 120 sites showed the presence of calculus with 49 sites in the range of 1.01 to $1.50 \mathrm{~mm}$ (mean $\pm \mathrm{SD}-1.45 \pm 0.55$ $\mathrm{mm}$ ). There was a significant statistical difference showing more CEJ-ABC distance with the presence of calculus $\left(\chi^{2}=44.8, p=0.001\right)$ as shown in Table 4 . The presence of plaque was divided based on the scores of plaque index. Group I -0.50 to 1.0 , group II -1.01 to 1.50 and group $\mathrm{III}-1.25$ to 1.5 . Mean $\pm \mathrm{SD}, \mathrm{CEJ}-\mathrm{ABC}$ distance in groups I, II is $1.17 \pm 0.48 \mathrm{~mm}$ and $1.33 \pm 0.52 \mathrm{~mm}$ respectively. There was a statistically significant difference $\left(\chi^{2}=27.6 \mathrm{df}\right.$ $=6 \mathrm{p}<0.001 \mathrm{HS}, \mathrm{Z}=3.74 \mathrm{p}<0.001)$ (Graph 4).

Total of 285 sites showed bleeding on probing with maximum number of sites (123) lying in a 1.01 to $1.50 \mathrm{~mm}$. Presence and absence of bleeding on probing is $1.21 \pm$ $0.47 \mathrm{~mm}$ and $1.18 \pm 0.50 \mathrm{~mm}$ respectively. Observations of study showed a positive correlation with bleeding on probing but the results were not statistically significant $\left(\chi^{2}=4.14 p=0.66\right)$. A total of 143 sites showed the presence of proximal caries with maximum number (66) of sites present in the range of 1.01 to $1.50 \mathrm{~mm}$. The mean $\pm \mathrm{SD}, 1.30 \pm 0.51$ with the presence of proximal dental caries and $1.13 \pm 0.50 \mathrm{~mm}$ with absence of proximal dental caries $\left(\chi^{2}=12.6, p=0.05\right)$. Proximal restorations were present at eight sites. For the

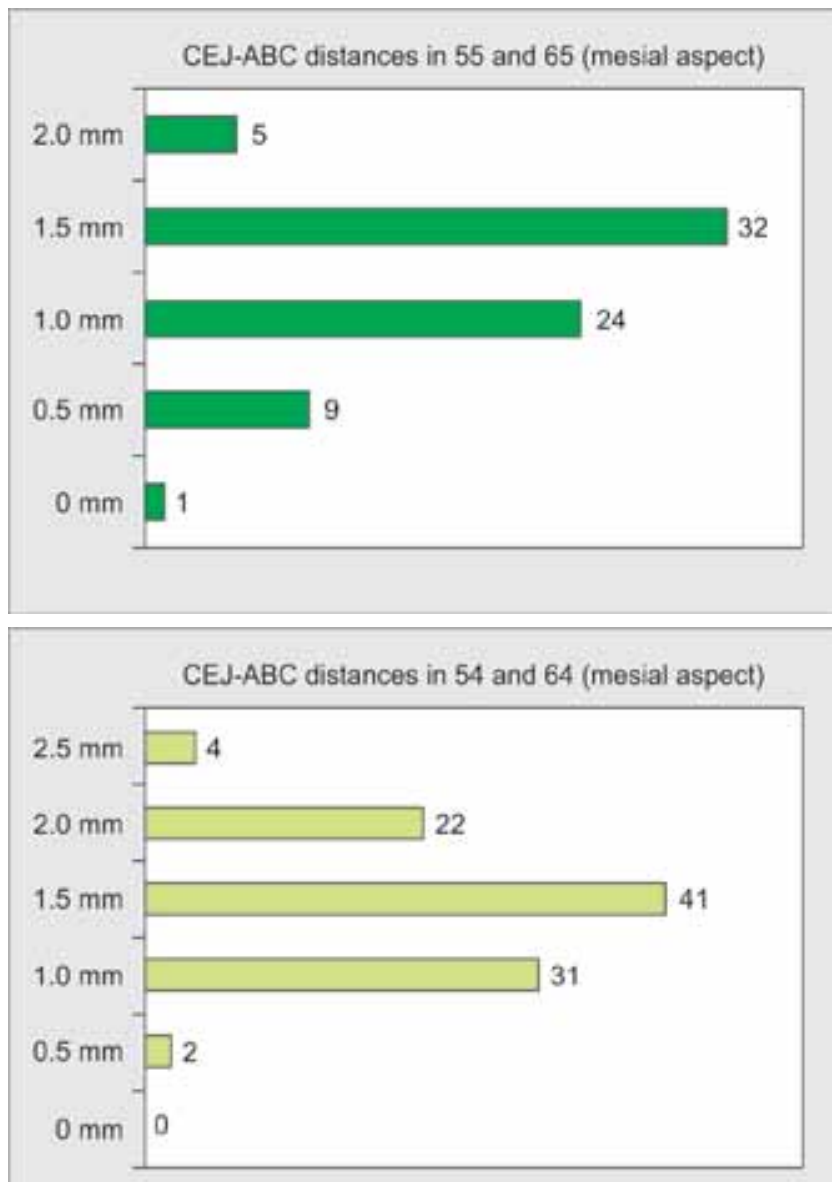

Graph 1: CEJ-ABC distances in deciduous molars 
Table 4: Comparison of CEJ-ABC distance with presence and absence of calculus

\begin{tabular}{|c|c|c|c|c|c|c|c|c|c|c|c|}
\hline \multirow[t]{2}{*}{ Factor } & \multirow[t]{2}{*}{ Status } & \multirow{2}{*}{$\begin{array}{l}\text { No. of } \\
\text { children }\end{array}$} & \multirow{2}{*}{$\begin{array}{l}\text { No. of } \\
\text { sites }\end{array}$} & \multicolumn{5}{|c|}{ Group I } & \multicolumn{2}{|c|}{ Group II } & \multirow[t]{2}{*}{ Mean $\pm S D$} \\
\hline & & & & 0 & $0.1-0.5$ & $0.51-1.0$ & $1.01-1.5$ & $1.51-2.0$ & $2.01-2.50$ & $2.51-3.0$ & \\
\hline \multirow[t]{3}{*}{ Calculus } & Present & 6 & 120 & $3 \pm 2.5$ & $5 \pm 4.2$ & $11 \pm 9.2$ & $49 \pm 40.8$ & $39 \pm 32.5$ & $12 \pm 10$ & $1 \pm 0.8$ & $1.45 \pm 0.55$ \\
\hline & Absent & 44 & 794 & $29 \pm 3.7$ & $37 \pm 4.7$ & $222 \pm 28$ & $352 \pm 44.3$ & $127 \pm 16.0$ & $23 \pm 2.9$ & $4 \pm 0.5$ & $1.16 \pm 0.47$ \\
\hline & \multicolumn{3}{|c|}{ Difference } & \multicolumn{5}{|c|}{$\chi^{2}=44.8 \mathrm{df}=6 \mathrm{p}<0.001 \mathrm{HS}$} & & & $Z=6.25 p<0.001$ \\
\hline
\end{tabular}

HS: Highly significant
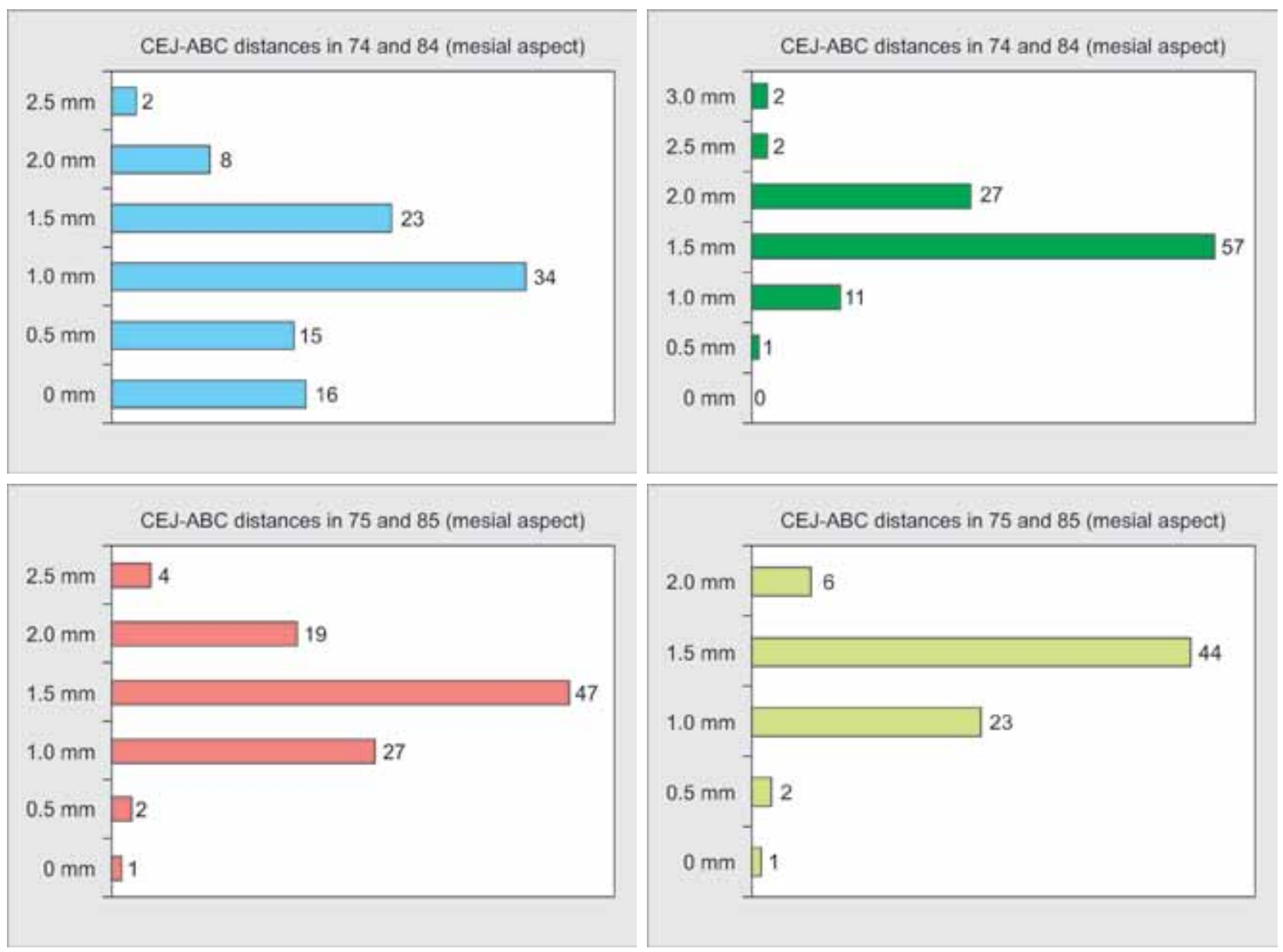

Graph 2: CEJ-ABC distances in deciduous mandibular molars

statistical analysis, the sites were too less to comment about the significance of result. Intraexaminer variability was checked for, the results showed no statistical significant difference $(\mathrm{p}=0.192)$ between first reading and reading taken after 4 weeks.

\section{DISCUSSION}

Periodontal diseases in children is usually limited to marginal gingivitis, though there are increasing evidences suggesting that periodontal destruction starts in primary dentition. Hence, biological changes that take place during childhood and adolescents should be taken into considerations, i.e. the structural and the functional changes of periodontal structures during eruption, the exfoliation of teeth, the establishment and maturation of oral microflora as well as gradual development of immune defense system. ${ }^{14}$ To date only a few previous studies attempted to investigate the normal alveolar crestal bone height of healthy children in the primary dentition. 3,7,9,13 Hence, our study aimed to determine the normal range for the radiographic distance between cementoenamel junction and alveolar bone crest in primary dentition to establish the baseline data in context to Indian scenario and to relate this distance to various physiological and pathological factors for the early assessment of periodontal disease.

Age group 6 to 8 years was taken as deciduous teeth are not getting replaced by permanent teeth and it has been documented that resorbing root of an exfoliating tooth may influence the radiopaque image of bone due to an effect on the mineral density of the marginal bone rather than effect on true bone height. ${ }^{3}$ 

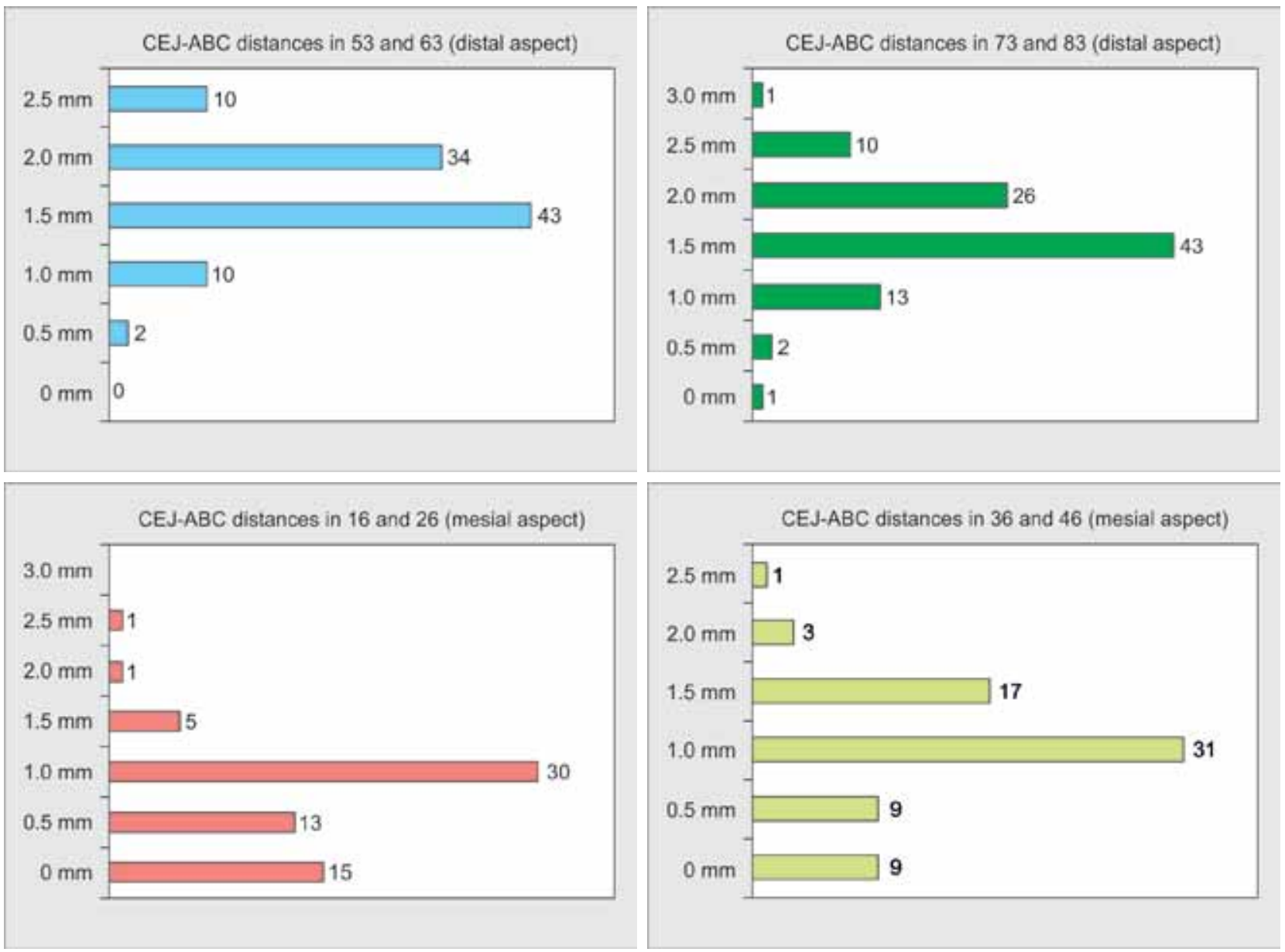

Graph 3: CEJ-ABC distances in maxillary and mandibular deciduous canine (distal aspect) and permanent first molar (mesial aspect)

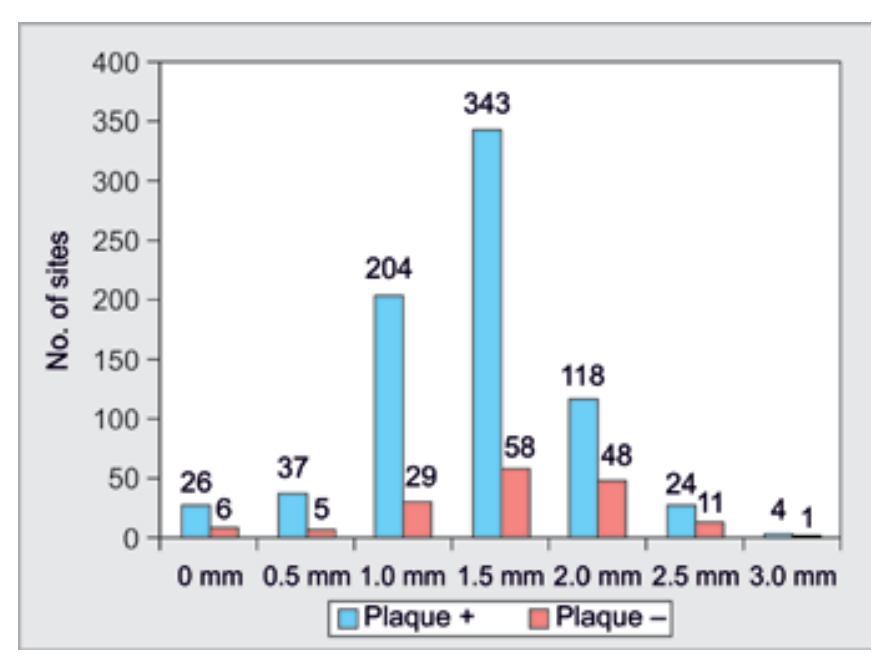

Graph 4: Distribution of subjects according to plaques at different CEJ-ABC distances

Radiographs have proved superior in diagnosing early periodontal lesions in some respect to clinical methods when comparing periodontal conditions on different occasions. As with clinical methods it may be difficult to keep diagnostic criteria stable overtime, while radiographic evaluation can be blinded. Moreover, radiographic examination gives the severity and extent of dental caries with much higher accuracy. ${ }^{15}$ Studies showed that radiographs may result in underestimation of bone loss due to lack of information of bone levels buccally and lingually. ${ }^{16}$ The present study concluded the distance 1.50 to $2.50 \mathrm{~mm}$ to be considered questionable and the distances greater than $2.50 \mathrm{~mm}$ to be considered as pathological/definite bone loss with a higher probability for future periodontal disease.

Our study was carried out by using bitewing radiograph, as perspective of alveolar bone crest and the changes in the bone height can be accurately assessed by comparison with the adjacent teeth, also the relationship of films and teeth to the central beam are essentially perpendicular and also due to small object to film distance, hence relative small image distortion is caused by the projection phenomenon. In addition to all these advantages it reduces the amount of exposure when compared with the periapical film. Also bite wing films are of particular value in detecting interproximal caries in early stages of development even before they are clinically apparent. ${ }^{17}$

There have been reported several methods of measuring the CEJ-ABC distance like by pair of radiographic binoculars with $2 \times$ magnification, ${ }^{3,18}$ view by projection on screen and measuring distance by divider and ruler, ${ }^{6,13}$ Troll magnifier binocuscope, ${ }^{19}$ use of different calipers Iwanson caliper, ${ }^{20}$ 
four inch Digimatic caliper ${ }^{9}$ (model \#500-320). Present study was carried out with the help of four inch Digimatic caliper having the accuracy to the extent of $0.01 \mathrm{~mm}$, while other caliper gives accuracy to the tune of $0.1 \mathrm{~mm} .^{20}$

In our study all the measurements were divided into 3 groups. Group I (no bone loss) 0 to $2 \mathrm{~mm}$, group II (questionable bone loss) 2 to $3 \mathrm{~mm}$, group III (definite bone loss) 3 to $4 \mathrm{~mm}$. This is in accordance with other studies. ${ }^{4,19,21} \mathrm{It}$ has been documented that lamina dura is absent even when the crest was normal, it seems preferable to ignore the lamina dura when examining a radiograph for crestal resorption. ${ }^{22}$

In our study, the CEJ-ABC distances of both right and left side with same sites were clubbed together for easier depiction and display of results, as other studies have shown that there is no significant difference between the measurements on both sides of the mouth. ${ }^{6,20}$ Our study showed that majority of the sites were $2.0 \mathrm{~mm}$ or less and were distributed around a mean of $1.0 \pm 0.5 \mathrm{~mm}(0.0-4.0 \mathrm{~mm})$. In maxillary, the primary 2nd molars and 1st molars (mesial) had CEJ$\mathrm{ABC}$ distance of $1.10 \pm 0.4 \mathrm{~mm}$ and the first primary molars (distal) had $1.26 \pm 0.4 \mathrm{~mm}$ while the deciduous canine had $1.49 \pm 0.4 \mathrm{~mm},{ }^{3,9}$ this is in slight variation with other studies. ${ }^{7}$ In mandible, 2nd primary molars (mesial and distal) had a distance of $1.23 \pm 0.4 \mathrm{~mm}$ and $1.14 \pm 0.4 \mathrm{~mm}$ respectively. 1st primary molars (mesial and distal) had $0.79 \pm 0.6 \mathrm{~mm}$ and $1.39 \pm 0.4 \mathrm{~mm}$ respectively and mandibular deciduous cuspid had $1.44 \pm 0.5 \mathrm{~mm}^{9}$ whereas few studies reported lesser values. ${ }^{3,7}$ These above mentioned variations may be due to differences in sample size, method of evaluating radiographs and inclusion of different risk factors in study (plaque, calculus, restorations and dental caries).

Study findings indicate mean CEJ-ABC distance for various primary tooth surfaces varied from 0.8 to $1.6 \mathrm{~mm}$. The smallest mean $(0.8 \mathrm{~mm})$ was found for the mandibular first molar (mesial). Possibly, this reflects a distortion due to the radiographic projection in this curving area of mandibular arch. ${ }^{3,6}$ While the highest CEJ-ABC distance $(1.49 \pm 0.4 \mathrm{~mm})$ was observed in maxillary cuspid. ${ }^{3,7}$ However, the distance of first primary molar (distal) was slightly greater than at the mesial of second primary molar, may be due to the convex shape of alveolar crest. Lack of parallelism, however, does not necessarily indicate a bone defect. $^{6}$

Present study results, in subjects, aged 6 to 8 years, showed majority of measurements were less than $2.0 \mathrm{~mm}$ and the levels increased with age in majority of teeth but was statistically nonsignificant. These changes were not in a simple linear fashion which is seen at 4 to 6 years of age and before puberty when the facial growth rate is maximum. ${ }^{9}$ As the subjects in the study lie between the two growth spurt period, ${ }^{8}$ during which the changes might be minimum, as well as narrow age interval may be reason for statistically nonsignificant difference. The increase in CEJ-ABC distance indicates that in primary dentition, tooth eruption may take place faster than alveolar bone deposition. ${ }^{14}$ The increase may be due to active and passive eruption, longer exposure to periodontal destructive factors and possibly change in the microflora nature with due course of time as the child grows. ${ }^{9}$ Accepting the fact that CEJ-ABC distance is increasing with age and is not equal for different teeth in a jaw, hence any attempt to establish general bone levels for diagnosis of periodontal disease in primary dentition might overestimate the normal CEJ-ABC distance and lower the sensitivity of radiographic diagnosis for identifying children with periodontal breakdown. ${ }^{8}$

Study results showed greater distance in boys $(1.25 \pm$ $0.5 \mathrm{~mm})$ compared to girls $(1.14 \pm 0.47 \mathrm{~mm})$, this may be due to greater amount of calculus formation there by leading to increased bone loss as compared to girls. ${ }^{9}$

Observations of the study showed that there is a greater CEJ-ABC distance with increased amount of plaque, similar to other studies stating that with the eruption of permanent teeth there will be increase in plaque accumulation and with increase in age there is a transition in composition of plaque microflora ${ }^{14}$ and the accumulated toxic products in plaque cause change in the level of alveolar bone. There has been positive correlation with presence of calculus and increased CEJ-ABC distance. The indirect effect of plaque accumulation and the extension can be augmented by the direct effects of toxic products retained with in calculus itself, ${ }^{23,24}$ while a few studies did not notice this change within. ${ }^{25}$ Radiographic bone loss may be an indication of periodontal disease; it does not discriminate between current periodontal diseases. Therefore, correct diagnosis of periodontitis requires concurrence of bleeding on probing and loss of periodontal support. ${ }^{4}$ When the study was conducted for effect of bleeding on probing on alveolar bone crest the result showed a positive correlation but was statistically insignificant. Restorations and the quality of restoration (overcontoured/undercontoured) play a very important role. In both over and under contoured restorations the proper physiologic contact area is disturbed thereby, causing a nidus of plaque accumulation, which predisposes to osseous defect. ${ }^{2}$

Attachment loss in normal deciduous teeth are not taken into consideration in our study because different studies have shown that the junctional epithelium migrates apically onto the primary tooth root surface and that this migration could be related to continuous eruption. ${ }^{6}$ In our study, the resorption of apical root less than $3 \mathrm{~mm}$ is considered as the safe value as the resorption more than $3 \mathrm{~mm}$ may affect the alveolar bone crest thus can give false reading of alveolar bone crest. As all the cases included in our study was less 
than $3 \mathrm{~mm}$, no correlation was done for this parameter. The criterion for measuring probing depth in our study, less than $4 \mathrm{~mm}$ was taken as absence of pocket taking into account in children the pseudo pockets, limiting the value of the periodontal probe as a diagnostic tool for screening purposes. ${ }^{16}$

It has been proved that there is a strong but indirect co-relation between proximal caries and increase in CEJ$\mathrm{ABC}$ distance, i.e. significant effect on alveolar bone, but not every case of proximal decay was accompanied by bone defect, this variation in CEJ-ABC distance can be due to the extent of decay, immune status and the time period for which decay is present, as decay facilitates the plaque, microorganisms and food impaction thus there by leading to bone loss. But valid comparisons between CEJ-ABC distance and local risk factors (dental caries, restoration) could not be established due to small sample size.

It is a documented fact that genetics also plays a very important role in depicting a particular type of condition/ lesion in some individuals with the presence of comparable amount of risk factors in all the study subjects. Similarly, the susceptibility of an individual to bone loss may reflect the immunological make up of that individual rather than the quantity of different variables (plaque, restoration, calculus, dental caries, bleeding on probing) on the teeth or the duration for which it has been present. ${ }^{26}$

To conclude, the mean CEJ-ABC distance in 6 to 8 years old children ranged between $1.0 \pm 0.5 \mathrm{~mm}$ for deciduous teeth and $0.6 \pm 0.4 \mathrm{~mm}$ for the mesial sites of the first permanent molars. There was no significant difference in CEJ-ABC distance with respect to ages 6, 7 and 8 years. Males have more distance than females. Dental caries, presence of calculus, amount of plaque were significantly associated with an increase in the CEJ-ABC distance. To have better insight into the association between bone loss, different risk variables (dental caries, plaque, restoration, calculus) and the type of dental treatment received by patient, further studies have to be carried out.

\section{REFERENCES}

1. Clerehugh V, Tugnait A. Diagnosis and management of periodontal diseases in children and adolescent. Periodontology 2000, 2001;26:146-168.

2. Bimstein E. Frequency of alveolar bone loss adjacent to proximal caries in the primary molars and its healing due to restoration of the teeth. Pediatr Dent 1992;14(1):30-33.

3. Sjodin B, Matsson L. Marginal bone level in the normal primary dentition. J Clin Periodontol 1992;19:672-678.

4. Da Silva PVS, De Souza IPR. Alveolar bone loss in primary dentition: State of the Art. J Clin Pediatr Dent 2004;29(2):139-142.

5. Keszthelyi G, Szabo I. Attachment loss in primary molars. J Clin Periodontol 1987;14(1):48-51.

6. Bimstein E, Soskolne AW. A radiographic study of interproximal alveolar bone crest between the primary molars in children. ASDC J Dent Child 1988;55(5):348-350.
7. Bimstein E. Radiographic diagnosis of the normal alveolar bone height in the primary dentition. J Clin Pediatr Dent 1995; 19(4): 269-271.

8. Shapira L, Tarazi E, Rosen L, Bimstein E. The relationship between alveolar bone height and age in the primary dentition. A retrospective longitudinal radiographic study. J Clin Periodontol 1995;22(5):408-412.

9. Needleman HL, Ku TC, Nelson L, Allred E, Seow WK. Alveolar bone height of primary and first permanent molars in healthy 7- to 9-year-old children. ASDC J Dent Child 1997;64(3):188-196.

10. Bajpai SC, Mehrotra KK, Gupta ND. Occurrence of incipient crestal bone loss. J Ind Dent Assoc 1995;66(2):44-45.

11. Kallestal C, Matsson, L. Criteria for assessment of interproximal bone loss on bite-wing radiographs in adolescents. J Clin Periodontol 1989;16(5):300-304.

12. Bimstein E, Delaney JE, Sweeney EA. Radiographic assessment of the alveolar bone in children and adolescents. Pediatr Dent 1988;10(3):199-204.

13. Bimstein E, Garcia-Godoy F. The significance of age, proximal caries, gingival inflammation, probing depths and the loss of lamina dura in the diagnosis of alveolar bone loss in the primary molars. ASDC J Dent Child 1994;61(2):125-128.

14. Bimstein E, Matsson L. Growth and development considerations in the diagnosis of gingivitis and periodontitis in children. Pediatr Dent 1999;21(3):186-191.

15. Källestal C, Matsson L. Marginal bone loss in 16 years old Swedish adolescents in 1975 and 1988. J Clin Periodontol 1991; 18(10):740-743.

16. Albandar J, Gjermo P. Associations between gingivitis, pocket depths and radiographic bone loss in interproximal areas in young adults. Scand J Dent Res 1983;91(5):371-375.

17. Wenzel A. Dental caries. In: White SC, Pharoah MJ, editors. Oral Radiology, Principles and Interpretation. 6th ed. Mosby: Elsevier; 2009. p. 270-271.

18. Sjödin B, Matsson L. Marginal bone loss in primary dentition. A survey of 7-9 years old children in Sweden. J Clin Periodontol 1994;21(5):313-319.

19. Bimstein E, Treasure ET, Williams SM, Dever JG. Alveolar bone loss in 5-year-old New Zealand children: Its prevalence and relationship to caries prevalence, socioeconomic status and ethnic origin. J Clin Periodontol 1994;21(7):447-450.

20. Bimstein E, Ranly DM, Skjonsby S, Soskolne WA. The effect of facial growth, attrition, and age on the distance from the cementoenamel junction to the alveolar bone crest in the deciduous dentition. Am J Orthod Dentofacial Orthop 1993;103(6):521-525.

21. Bimstein E, Shapira L, Landau E, Sela MN. The relationship between alveolar bone loss and proximal caries in children; Prevalence and microbiology. ASDC J Dent Child 1993;60(2):99-103.

22. Stoner JE. The value of the bitewing radiograph in the diagnosis of dental disease in young subjects. ASDC J Dent Child 1974; 41(3): 190-193.

23. Mandel ID, Gaffar A. Calculus revisited: a review. J Clin Periodontol 1986;13(4):249-257.

24. Addy M, Koltai R. Control of supragingival calculus. Scaling and polishing and anticalculus toothpastes: an opinion. J Clin Periodontol 1994;21(5):342-346.

25. Whittaker DK, Molleson T, Nuattall T. Calculus deposits and bone loss on the teeth of Romano-British and eighteenth-century Londoners. Arch Oral Biol 1998;43(12):941-948.

26. Hull PS, Hillam DG, Beal JF. A radiographic study of the prevalence of chronic periodontitis in 14 years old English school children. J Clin Periodontol 1975;2(4):203-210. 